\section{Política y Sociedad}

ISSN-e: 1988-3129

\title{
Ciudadanía fragmentada: entre la representación y la deliberación
}

\author{
Jaime Minguijón ${ }^{1}$, Eva María Tomás-del Río², Diego Gastón-Faci ${ }^{3}$
}

Resumen. ¿Responden las percepciones y comportamientos de la ciudadanía a los requisitos planteados por la democracia deliberativa? Este trabajo realiza un análisis de la magnitud y profundidad de la crisis de la democracia representativa, para, a partir de las claves que caracterizan este complejo contexto, indagar en las propuestas planteadas para combatir esta crisis. Entre ellas, destacan un conjunto de propuestas en torno a la democracia deliberativa, que suponen pasar de una concepción de ciudadano pasivo, que se limita a emitir el voto cada cuatro años, a un ciudadano activo que se implica en el discurrir cotidiano de los asuntos públicos.

Posteriormente, se aborda el objeto central de este trabajo: identificar la mayor o menor predisposición de la ciudadanía española a desarrollar las percepciones y comportamientos que exige una democracia deliberativa. Para ello, se radiografía la ciudadanía española a través de un análisis de datos secundarios procedentes de los últimos barómetros del CIS.

Los resultados del análisis evidencian la existencia de una ciudadanía fragmentada que adopta una heterogeneidad de posiciones en el contínuum representación-deliberación.

Palabras clave: democracia deliberativa; participación ciudadana; crisis democrática.

\section{[en] Fragmented citizenship: between representation and deliberation}

Abstract. Do citizens' perceptions and behaviors respond to the requirements formulated by deliberative democracy? This work analyses the magnitude and depth of the crisis of representative democracy, to, based on the keys that characterize this complex context, inquire about the proposals that scientific literature poses to combat this crisis. Among them, are set of approaches around deliberative democracy stand out, which involve moving from a conception of passive citizen, which is limited to casting the vote every four years, to an active citizen involved in the daily life of public affairs.

Subsequently, the central objective of this paper is addressed: to identify the greater or lesser predisposition of Spanish citizens to develop the perceptions and required by a deliberative democracy. To do this, the Spanish citizenship is radiographed through an analysis of secondary data from the last CIS barometers.

The results of the analysis show the existence of a fragmented citizenship that adopts heterogeneity of positions in the representation-deliberation continuum.

Keywords: deliberative democracy; citizen participation; democratic crisis.

Sumario: 1. Introducción 2. Claves teóricas para la comprensión del problema 3. Sobre la actitud de la ciudadanía hacia la democracia 4. Sobre las vías de participación 5. Hacia la construcción de una tipología sobre el comportamiento participativo 6. Conclusiones 7. Bibliografía.

Como citar: Minguijón, J.; Tomás-del Río, E. Maa; Gastón-Faci, D. (2021). Ciudadanía fragmentada: entre la representación y la deliberación. Polit. Soc. (Madr.) 58(3), 65737. https://dx.doi.org/10.5209/poso.65737

\section{Introducción}

Mucho se ha escrito sobre la crisis de la democracia representativa ${ }^{4}$ o sobre la desafección de la ciudadanía respecto de la política5. Tanto que algunos autores hablan de que "la crisis nunca ha sido la excepción a la regla; más bien, es una característica inherente de la democracia y puede incluso verse como una señal de que está funcionando" (Ercan y Gagnon, 2014: 6). Pero la situación actual parece tener una componente más crítica, como si nos encontrásemos ante una grave crisis de legitimidad, avalada por una constante valoración negativa

\footnotetext{
Universidad de Zaragoza. (España)

E-mail:jmingui@unizar.es

2 Universidad de Zaragoza. (España)

E-mail: evatomas@unizar.es

3 Universidad de Zaragoza. (España)

E-mail: dgaston@unizar.es

4 Un buen análisis, algo lejano en el tiempo, pero todavía de plena vigencia, puede encontrarse en Abal (2004). Asimismo, cabe destacar Valencia et al. (2013).

O “desciudadanización”, haciendo referencia al marcado desinterés de la ciudadanía por la cosa pública (Piedra Buena, 2007: 196).
} 
por parte de los ciudadanos sobre los partidos, la política y las instituciones, hasta el punto de que puede llegar a estar en riesgo de acabar con el mismo sistema democrático (Tormey, 2014; Stefan Foa y Mounk, 2016; Przeworski, 2019).

Aunque algunos autores ponen en duda la existencia de esa crisis (Merkel, 2014), lo cierto es que el conjunto de la literatura científica ofrece un diagnóstico contundente en este sentido. En España, la constatación de una situación de crisis de la democracia viene avalada por la opinión de la ciudadanía reflejada en los Barómetros del CIS:

- El porcentaje de ciudadanos que opina que los/as políticos/as en general, los partidos y la política son uno de los tres principales problemas de nuestro país oscila entre el $21 \%$ y el $30 \%$ entre 2015 y 2018. Esa cifra se dispara a partir de 2019 (llega al 49,5\% en diciembre) ${ }^{6}$.

- En esas mismas fechas, la corrupción y el fraude son uno de los tres principales problemas para un tercio de la ciudadanía, aunque ese porcentaje desciende a partir de julio de 2019 , llegando a un 16,9\% en marzo de 2020.

- Entre 2014 y 2016, un 41\%-43\% de los ciudadanos opina que "es mejor no meterse en política".

- Con la sola salvedad de la religión, la política es el aspecto que menor importancia tiene para la vida de los españoles. En concreto, en el periodo que se introdujo esta pregunta, de una valoración de 1 a 10 sobre cada aspecto, la política obtiene los siguientes valores: 4,35 (octubre de 2015), 4,64 (octubre de 2016), 4,58 (octubre de 2017).

- Entre 2015 y 2018, cerca de la mitad de los españoles habla raramente o nunca con amigos y familiares de política.

Sin embargo, esta pretendida crisis, más allá de opiniones, no se ve, de facto, plenamente refrenda por el comportamiento de la ciudadanía, ya que, elección tras elección, se viene legitimando el sistema con la participación masiva en las diferentes elecciones generales, como puede comprobarse en el hecho de que desde la llegada de la democracia (excepto en 1979), la participación electoral ha oscilado entre el $70 \%$ y el $80 \% 7$.

En el caso de España, esta paradoja llevó a Sanz (2002) a tildar como cínica la relación de la ciudadanía con la política, relación muy oportunamente explicada por el Colectivo IOÉ (2008: 320). Pero no puede olvidarse que esta situación está en consonancia con lo que sucede en otros países democráticos, en los que, en un ambiente similar, se mantiene el apoyo a los valores que sustentan los sistemas democráticos (Pharr et al., 2000: 9).

Lo que se pretende en este artículo es analizar someramente las causas de la crisis y poner de relieve las principales soluciones que se proponen a la misma, centrando el foco específicamente en la democracia deliberativa. A partir de ahí, se analizarán las diferentes fórmulas de participación inherentes a este nuevo tipo de democracia y se compararán con las propias de la democracia representativa, así como con otras fórmulas de participación no institucional, con el fin de conocer en qué medida la ciudadanía española refrenda (o no), con sus percepciones y sus acciones, este tipo de soluciones a la crisis de la democracia. Para ello nos serviremos de diferentes fuentes de información de carácter secundario, entre las que destacan los barómetros del CIS.

La respuesta esperada y, en este sentido, la hipótesis de trabajo, es que existe un posicionamiento diverso ante estas nuevas alternativas, por lo que se puede concluir que el cuerpo soberano está fragmentado y encara de forma diferente estas nuevas experiencias democráticas.

\section{Claves teóricas para la comprensión del problema}

La aparente paradoja señalada anteriormente ya había sido el foco de atención de un informe monográfico que analizaba de forma comparada las principales democracias en América Latina, Asia y Europa Central (Torcal y Montero, 2006). Varios de los autores que participaron en ese informe resolvieron la paradoja, y llegaron a la conclusión de que los elementos que coadyuvan al menoscabo de la política institucional no significan necesariamente (de hecho, casi nunca lo significan en las democracias consolidadas) una erosión del apoyo al sistema democrático en sí mismo (Offe, 2006; Gunther y Montero, 2006) ${ }^{8}$.

Esto es lo que refleja un estudio reciente del CIS (Estudio 3223, de 2018), según el cual, a juicio de los entrevistados, la mayoría de los ciudadanos opina que está poco o nada satisfecho con el funcionamiento de

Esa posibilidad de respuesta desaparece en enero de 2020, con lo que las comparaciones son imposibles a partir de esa fecha. Y reaparece en junio de 2020, con un valor muy bajo (23,9\%), aunque es cierto que las comparaciones son difíciles, porque se hicieron telefónicamente por la pandemia, en vez de presencialmente. Y así se ha hecho hasta el último barómetro a la fecha de la redacción de esta nota (mayo de 2021).

Aprovechamos esta nota a pie de página para señalar que se va a seguir este criterio a lo largo de todo este artículo, por lo que las comparaciones terminarán en marzo de 2020. Este criterio lo fija el propio CIS cuando presenta sus series de indicadores hasta esa misma fecha.

La excepción ha sido la del $20 \mathrm{~N}$ de 2019 , en la que la participación se quedó en el $66,2 \%$.

En realidad, todos ellos parten de la propuesta de Easton (1975), que diferencia entre el apoyo a la democracia desde una perspectiva específica (los políticos y las instituciones concretas) o desde una perspectiva difusa (al sistema democrático representativo). 
la democracia española $(55 \%)^{9}$, a pesar de que la democracia en sí misma obtiene un amplio respaldo (es el sistema de gobierno preferido para el $86 \%$ de la población).

Por lo tanto, se debe profundizar en las causas de la dimensión específica de la crisis de la democracia. Uno de los autores en nuestro entorno que ha trabajado esta cuestión es Quim Brugué (2010: 22-23), que habla de una doble crisis de legitimidad del sistema representativo, tanto en los imputs (desconfianza en los mimbres del sistema político-administrativo), como en los outputs (insatisfacción con el resultado del sistema políticoadministrativo).

Como puede comprobarse, Brugué pone el acento en la ciudadanía, es decir, que para él la crisis de la democracia reside fundamentalmente en cómo el pueblo percibe el sistema democrático. Esta apreciación es importante, puesto que no es lo mismo la percepción ciudadana sobre la calidad de la democracia que los indicadores objetivos, como puede comprobarse de la siguiente tabla, extraída del Informe Sobre la Democracia en España de 2020 de la Fundación Alternativas:

Gráfico 1. Evolución de la evaluación de la democracia española (2008-2020)
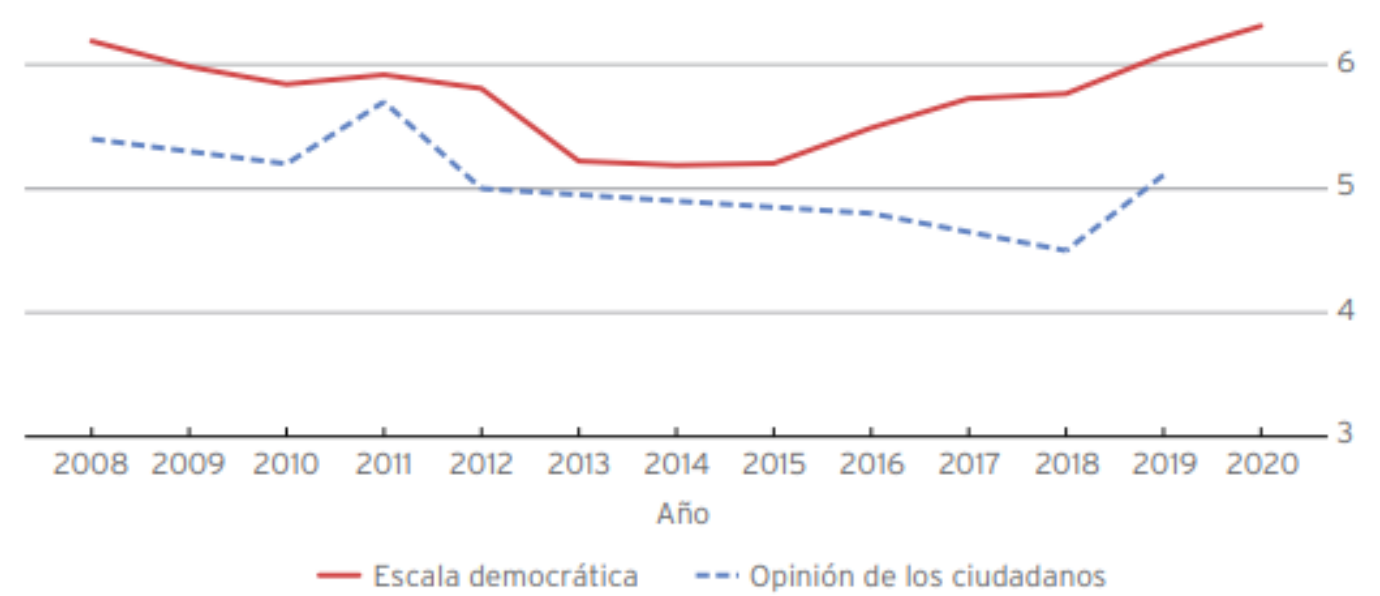

Fuente: Escobar y Cabrera (2021: 226).

Hasta 2015 (con la excepción de 2011), las dos líneas (que expresan la percepción ciudadana y el indicador objetivo) corrían paralelas, aunque siempre la percepción es inferior a lo que arrojan los datos objetivos. Sin embargo, a partir de ese año se separan; crece el indicador objetivo y desciende el subjetivo (excepto en 2019, que sube).

En todo caso, aun con las diferencias observadas en los últimos años, lo cierto es que, siguiendo a Koselleck (2007: 241), detrás de toda crisis subjetiva hay una crisis objetiva, por lo que hay que preguntarse qué hay detrás de esa percepción, desde el punto de vista de los procesos sociales y políticos de largo alcance. Muchos autores han abordado esta cuestión, pero, atendiendo a los clásicos, se puede poner la atención en Dahrendorf (2002) o Bobbio (1985), para quienes se produce en gran medida un desacoplamiento entre la capacidad de control por parte de la ciudadanía y los poderes, más o menos ocultos, que realmente inciden en la toma de decisiones, aspecto en el que profundiza Subirats (2005: 4).

Pero más allá de estos elementos de fondo y de largo alcance, tampoco puede olvidarse que otros elementos coyunturales pueden coadyuvar a esa crisis. En concreto, algunos estudios recientes, centrados en la realidad española, demuestran que la crisis económica, la desigualdad, la caída del PIB y la corrupción aumentan la desconfianza en toda la población (De Marco et al., 2018: 7). En este sentido, habría que poner de relieve, igualmente, el poder multiplicador de las redes y los medios de comunicación, que amplifican y resaltan los aspectos negativos de la política (Innerarity, 2015). También las consecuencias de la crisis económica (Torcal, 2014), dado que la insatisfacción creciente con la representación política es muy sensible a la situación del empleo, tal y como se recuerda en el último informe FOESSA (Fernández, 2019: 180).

Resumiendo las diferentes aportaciones, podría decirse que "el primer problema estructural es que la gente no cree en la representación sobre la que se sustenta la democracia. El segundo problema estructural es que la democracia está permanentemente en crisis de gobernabilidad, pues ha sido ineficaz contra la corrupción y otros problemas como las mafias y la crisis ecológica" (Roll, 2018:11). 
Una vez hecho el diagnóstico, la cuestión reside en vislumbrar cuál es la propuesta adecuada para combatirlo. Hay quienes propugnan una reducción de las esferas democráticas como solución a la crisis ${ }^{10}$, quienes defienden que parte de la ciudadanía estaría más cómoda con un gobierno de expertos ${ }^{11}$, y hay quienes apuestan por una ampliación o perfeccionamiento de la misma ${ }^{12}$. Con el objeto de profundizar en esta última perspectiva, la literatura científica habla de dos posibles desarrollos del perfeccionamiento de la democracia:

a) De un lado, los planteamientos deliberativos de la teoría democrática y las nuevas propuestas sobre la calidad, representatividad y rendición de cuentas (accountability) de las instituciones políticas (Isunza, 2015; Neblo et al., 2010).

Los conceptos de participación ciudadana y de democracia deliberativa se encuentran íntimamente ligados, ya que la definición de la segunda suele englobar a la primera (por ejemplo: Velasco, 2009: 75). Partiendo de la clasificación propuesta por Pindado, de las cuatro posibles políticas de participación, se está haciendo referencia a la que denomina "de calidad democrática", es decir, la que "pretende armonizar una arquitectura institucional útil y eficaz con el desarrollo de canales, espacios y procesos de debate e implicación ciudadana en los asuntos públicos" (Pindado, 2009: 122). Se trata de una participación controlada y organizada desde las instituciones político-administrativas (Ganuza y Francés, 2012; Martínez-Palacios, 2021).

La democracia deliberativa no supone la sustitución de la democracia representativa por otra, sino que viene a ser un desarrollo de esta última, ampliada con un nutrido abanico de estrategias y metodologías que la hacen posible, viable y eficaz (Carrasco y Rodríguez Ruíz, 2019; García-Espín y Jiménez, 2017). Esta idea va en la línea de las conclusiones alcanzadas por algunos estudios, que infieren que, en general, la ciudadanía desea ser más abierta y participativa, aunque ello no modifica sustancialmente la defensa del sistema de delegación del proceso de toma de decisiones que supone la democracia representativa (Ganuza et al., 2017; García-Espín et al., 2017).

b) De otro lado, las experiencias de participación no institucional o pseudoinstitucional, que harían referencia a una forma de participación en la que ya no se produce una participación "por invitación" sino una participación "por irrupción" (Ibarra y Ahedo, 2008) ${ }^{13}$.

La participación "no institucional" ha sido objeto de muchos análisis. Ya en el siglo pasado Kaase (1999) identificó una relación negativa entre la participación institucional y la no institucional, hecho demostrado más recientemente por Braun y Hutter (2014). La hipótesis, para algunos autores, es que el alejamiento de la política institucional y el acercamiento a fórmulas no institucionales hablan más bien de una repolitización de la ciudadanía (McCaffrie y Akram, 2016).

Es desde el campo del estudio de los movimientos sociales desde donde se puede arrojar algo de luz a las formas no institucionales de participación, que tienden a presentar de manera muy difusa. Tradicionalmente, la acción no institucional se ha identificado con el conjunto de repertorios de acción colectiva vinculados con la "calle": la manifestación, la huelga, los actos de desobediencia civi1 $^{14}$, las peticiones, la concentración, las sentadas, los cortes de carretera, los escraches, etc. ${ }^{15}$. Otros autores incluyen la ocupación de algún edificio o la violencia contra la propiedad (Tejerina et al., 2005; CIS, 2002), e incluso se introducen acciones que no se ejecutan de forma masiva en el espacio público, como los boicots a determinadas empresas o países, abogando por no comprar sus productos o servicios ${ }^{16}$.

En este sentido, se incluirían todas aquellas prácticas participativas que se desarrollan al margen o con un elevado grado de autonomía respecto de las instituciones gubernamentales. Como en el caso de las experiencias de participación institucional, pueden presentar diferentes grados de formalidad, pero lo que las diferencia es que su liderazgo no recae en las administraciones públicas (Martí-Costa, 2009).

Lo que tienen en común las salidas de perfeccionamiento de la democracia es que dan por hecho la presencia de un "giro deliberativo" (Dryzek, 2000) en la política, lo que implica la existencia de un tipo de ciudadano particular, dispuesto a razonar, a exponer argumentos, a escuchar a los demás y a reflexionar, es decir, un ciudadano activo (Cohen y Arato, 2000).

10 Lo que podría denominarse como una "salida restrictiva" a la crisis de la democracia liberal (Rodríguez, 2013: 666), que se funda en el famoso informe de Crozier et al. (1975).

La Stealth Democracy, de Hibbing y Theiss-Morse (2002).

12 Serían las salidas elitistas o populistas a la crisis de la democracia representativa de las que hablaba Nino (1997: 214).

Ver especialmente el capítulo de Ibarra titulado "Participación y poder: de la legitimación al conflicto" (pp. 37-55).

14 Estaríamos hablando del "derecho a anular una resolución adoptada por otro", que caracteriza la prevención para limitar el poder (Rosanvallon, 2006).

15 En todo caso, cabría una reflexión en torno al proceso de "normalización" de este tipo de acciones (especialmente, la manifestación y la huelga), con lo que se podría llegar a cuestionar su carácter "no institucional” (Jiménez, 2011; Casquete, 2006). Aun así, seguimos manteniendo la perspectiva adoptada en el artículo, desde el momento en que no son acciones por invitación, sino por irrupción.

16 Partiendo del boicot empresarial (Friedman, 1991), este tipo de actuaciones se han extendido para luchar contra las prácticas de determinados países y/o gobiernos (García y Novo, 2017), hecho bien descrito por Beck (1994: 66): "Los ciudadanos están descubriendo que el acto de comprar puede ser un voto directo que siempre pueden utilizar de forma política". 
Precisamente, el objetivo de este trabajo consiste en radiografiar a la ciudadanía española con el fin de conocer en qué medida refrenda, con sus percepciones y sus acciones, cada uno de los elementos expuestos más arriba, desde los que implican la democracia representativa a los que suponen la democracia deliberativa, en sus dos vertientes: la más institucional o la menos institucional.

Para ello, se tratará de ir un poco más allá de lo apuntado por Font et al. (2012) ${ }^{17}$, que se centraron en demostrar el grado de acercamiento o de acuerdo (o no) de la ciudadanía a la democracia representativa (o sigilosa) y a la democracia deliberativa. Lo que se trata de analizar en el presente artículo desborda lo comentado en ese estudio en el sentido de que nos fijamos tanto en un estado de opinión previo (percepciones y opiniones previas necesarias para la acción), como en las actitudes de la ciudadanía en torno a comportamientos que suponen, de facto, la aceptación de un tipo u otro de democracia, más allá de las opiniones expresadas (por ejemplo, ir o no a manifestaciones).

En este sentido, bajo la premisa de la complejidad del asunto analizado, la hipótesis subyacente del trabajo es que existe un alto grado de heterogeneidad en la población española, es decir, que sería científicamente incorrecto responder a estas preguntas de forma genérica, como ya han apuntado algunos autores (García Espín et al., 2017; Walker et al., 2015; Lee, 2011). Por ello proponemos establecer una tipología en función de las percepciones y comportamientos que permiten inducir el acercamiento o alejamiento de la ciudadanía española a esos tipos de democracia.

El hecho es que es preciso conocer si los modelos de perfeccionamiento de la democracia, a través de las diferentes estrategias que han sido analizadas, se asientan sobre las viejas desigualdades sociales, lo que dificultaría la profundización en la democracia y el incremento de la igualdad que parecieran prometer, tal y como proponen Walker et al. (2015: 18). En este sentido, un análisis profundo de cómo los diferentes perfiles de ciudadanos perciben los distintos tipos de participación ayudará a evaluar lo que realmente está en juego en la supuesta revolución de la participación.

\section{Sobre la actitud de la ciudadanía hacia la democracia}

Anteriormente, se ha podido comprobar el alto nivel de legitimación del sistema representativo en España a través del voto en las elecciones generales. Este comportamiento en exclusiva hablaría de un ciudadano claramente pasivo, alejado de las características que exige al nuevo ciudadano el perfeccionamiento de la democracia. Veamos en qué medida esto es así:

Tabla 1. A través del voto la gente como Ud. puede influir en lo que pasa en la política. Varios años

\begin{tabular}{|l|c|c|}
\hline Años & $\begin{array}{c}\text { Muy de acuerdo } \\
\text { De acuerdo }\end{array}$ & $\begin{array}{c}\text { En desacuerdo } \\
\text { Muy en desacuerdo }\end{array}$ \\
\hline $\mathbf{2 0 1 6}$ & $63,8 \%$ & $31,3 \%$ \\
\hline $\mathbf{2 0 1 8}$ & $66,3 \%$ & $28,5 \%$ \\
\hline $\mathbf{2 0 1 9}$ & $70,0 \%$ & $25,4 \%$ \\
\hline
\end{tabular}

Fuente: CIS: Estudio 3145 (julio 2016), Estudio 3226 (octubre 2018) y

Estudio 3240 (febrero 2019).

Más de un 60\% en los últimos años está de acuerdo con esa afirmación, y se incrementa hasta 2018, año en que lo opina el 70\% de la población. A continuación, se va a cruzar la información del barómetro de 2019 con la que hace referencia al recuerdo de la participación en las elecciones generales de 2016:

Tabla 2. A través del voto, la gente como Ud. puede influir en lo que pasa en la política vs.

Votó (o no) en las elecciones generales. 2016

\begin{tabular}{|l|c|c|}
\hline & Votó & No votó o NS/NC \\
\hline $\begin{array}{l}\text { Muy de acuerdo o } \\
\text { de acuerdo }\end{array}$ & $72,2 \%$ & $56,7 \%$ \\
\hline $\begin{array}{l}\text { En desacuerdo o } \\
\text { muy en desacuerdo }\end{array}$ & $23,9 \%$ & $34,2 \%$ \\
\hline
\end{tabular}

Fuente: CIS: Estudio 3240 (2019).

17 Un desarrollo más reciente de esta propuesta la encontramos en Del Rio et al. (2016) y en Fernández (2018). 
Se observa una relación significativa ${ }^{18}$ entre las dos variables, en el sentido de que el hecho de haber ido a votar (o no) es dependiente del grado de acuerdo con la frase "A través del voto la gente como Ud. puede influir en lo que pasa en la política".

Por otra parte, los barómetros del CIS también ofrecen algunas pistas indirectas acerca de la predisposición o capacidad subjetiva que las personas tienen en torno a su identificación con algunas de las características propias de lo que hemos denominado ciudadanía activa: la autopercepción sobre la comprensión de la política y sobre el hecho de considerarse un ciudadano que entiende de política.

Tabla 3. Generalmente, la política le parece tan complicada que la gente como Ud. no puede entender lo que pasa. Varios años

\begin{tabular}{|l|c|c|c|}
\hline Años & De acuerdo & $\begin{array}{c}\text { Ni de acuerdo ni en } \\
\text { desacuerdo }\end{array}$ & En desacuerdo \\
\hline $\mathbf{2 0 1 4}$ & $36,9 \%$ & $15,0 \%$ & $45,4 \%$ \\
\hline $\mathbf{2 0 1 5}$ & $39,1 \%$ & $12,4 \%$ & $46,2 \%$ \\
\hline $\mathbf{2 0 1 6}$ & $36,9 \%$ & $15,0 \%$ & $45,5 \%$ \\
\hline
\end{tabular}

Tabla 4. En general, se considera un/a ciudadano/a que entiende de política. Varios años

\begin{tabular}{|l|c|c|c|}
\hline Años & De acuerdo & $\begin{array}{c}\text { Ni de acuerdo ni en } \\
\text { desacuerdo }\end{array}$ & En desacuerdo \\
\hline $\mathbf{2 0 1 4}$ & $35,6 \%$ & $22,6 \%$ & $39,4 \%$ \\
\hline $\mathbf{2 0 1 5}$ & $36,1 \%$ & $20,9 \%$ & $40,2 \%$ \\
\hline $\mathbf{2 0 1 6}$ & $37,7 \%$ & $23,0 \%$ & $36,6 \%$ \\
\hline
\end{tabular}

Las dos tablas anteriores introducen un elemento más de diversidad en la caracterización de la población española respecto del tema que se está abordando. Si se cruzan estas dos variables en el último de los barómetros en el que se hace esa pregunta (octubre de 2016), se pueden inferir dos tipos principales de perfiles de ciudadanos claramente diferenciados.

Tabla 5. En general, se considera un/a ciudadano/a que entiende de política vs.

Generalmente, la política le parece tan complicada que la gente como Ud. no puede entender lo que pasa

\begin{tabular}{|l|l|c|c|c|}
\hline \multirow{2}{*}{$\begin{array}{l}\text { Generalmente, la política le pa- } \\
\text { rece tan complicada que la gen- }\end{array}$} & \multicolumn{3}{|c|}{ En general, se considera un/a ciudadano/a que entiende de política } \\
\cline { 2 - 5 } $\begin{array}{l}\text { te como Ud. no puede entender } \\
\text { lo que pasa }\end{array}$ & $\begin{array}{l}\text { De acuerdo } \\
\text { De acuerdo }\end{array}$ & $6,6 \%$ & $\begin{array}{c}\text { Ni de acuerdo ni en } \\
\text { desacuerdo }\end{array}$ & En desacuerdo \\
\hline $\begin{array}{l}\text { Ni de acuerdo ni } \\
\text { en desacuerdo }\end{array}$ & $3,4 \%$ & $5,9 \%$ & $23,7 \%$ \\
En desacuerdo & $27,4 \%$ & $6,7 \%$ & $4,6 \%$ \\
$7,2 \%$
\end{tabular}

Fuente: barómetro, CIS: octubre, 2016.

Por un lado, un 40,9\% de la población opina que entiende de política y no la considera complicada; y por otro lado, un $34,2 \%$ de la ciudadanía considera la política como algo complejo (lo que dificulta su comprensión) y no entiende de política. El tercer grupo que dejaremos fuera del análisis $(24,9 \%)$ estaría compuesto por un tipo de ciudadano que expresa ambivalencia en sus afirmaciones, al que habría que sumar el pequeño porcentaje de personas que no contesta.

En el primer caso, estaríamos ante un ciudadano activo "en potencia"; en el segundo caso, ante un ciudadano que cree no disponer de las competencias necesarias para dar ese paso, con lo que necesariamente habría de ubicarse dentro de la ciudadanía pasiva. Es interesante conocer, para cada bloque, una serie de características, centradas en las siguientes variables:

- Sexo: hombre y mujer.

- Grupo de edad: menores de 30 años, de 30 a 64 años y de 65 años o más.

- Dimensión rural/urbano, dividida en tres categorías: de 2000 habitantes o menos; de 2001 a 400.000 habitantes y de más de 400.000 habitantes.

18 Cuando se indique en este y en los siguientes comentarios que se observa una relación significativa, se ha aplicado la prueba de la ji cuadrado para una p $>0,05$. Solo en el caso de que la variable dependiente sea ordinal, se ha aplicado el índice de correlación de Spearman. 
- Nivel educativo ${ }^{19}$, con cuatro categorías: cuatro categorías: Sin estudios, Estudios primarios, Secundarios y Estudios Superiores.

- Estatus socioeconómico, siguiendo los criterios del CIS, con cinco categorías: Clase alta/media-alta, Nuevas clases medias, Viejas clases medias, Obreros/as cualificados/as y Obreros/as no cualificados/as.

- $\quad$ La autoubicación ideológica ${ }^{20}$, con tres categorías: Izquierda, Centro y Derecha.

Los resultados obtenidos de cruzar esa nueva variable compuesta por las dos precedentes, que hacen referencia a la comprensión de la política, y las variables sociodemográficas, ponen de manifiesto que existe una relación significativa entre ellas y el nivel de entendimiento de la política:

- En primer lugar, respecto al hecho de ir a votar o no: el $44 \%$ de los que votaron entiende la política y no les parece complicada. Por el contrario, solo opina lo mismo el $22 \%$ de los que no votaron.

- Respecto al sexo, por ejemplo, el $28 \%$ de los hombres y el $40 \%$ de las mujeres creen que "No entienden de política y esta es complicada". Por el contrario, el $46 \%$ de los hombres y el $36 \%$ de las mujeres opina que "Entienden de política y esta no es complicada".

- En lo que hace referencia a la edad, las personas con mayor nivel de entendimiento son los adultos $(47 \%)$, mientras que los que manifiestan en mayor medida que no la entienden y es complicada son las personas mayores $(48 \%)$.

- Igualmente, conforme aumenta el tamaño de hábitat hay un mayor nivel de comprensión: es del 26\% para el medio rural, del $40 \%$ para el intermedio y del $51 \%$ para el urbano.

- Algo similar ocurre en torno al nivel de estudios de la persona entrevistada. Conforme aumenta el nivel de estudios hay un mayor nivel de comprensión: es del 7,7\% para las personas sin estudios, del $16 \%$ para los primarios, del $41 \%$ para los secundarios y del $69 \%$ para los universitarios.

- Igualmente, conforme se asciende en la escala social, aumenta el nivel de comprensión: por ejemplo, un $26 \%$ para los obreros no cualificados y un $66 \%$ para las clases altas o medio altas.

- Finalmente, aunque en menor medida, también hay diferencias en torno a la ideología. Son las personas de izquierdas las que más consideran que entienden y comprenden la política (53\%), en comparación a las del centro y las de la derecha ( $42 \%$ en ambos casos).

\section{Sobre las vías de participación}

Se comenzó el análisis con las vías institucionales de participación. Con la finalidad de mantener la homogeneidad de los análisis, se va a seguir con el estudio de la relación entre el hecho de haber votado o no con otras variables en referencia al barómetro que venimos utilizando:

- Edad: cuanto más mayor, más se vota ( $81,5 \%$ en los menores de 30 años; el $91,5 \%$ en los mayores de 65 años).

- Nivel de estudios: cuando más estudios se tiene, más se vota $(83,9 \%$ de las personas sin estudios; el $93,4 \%$ de las personas con estudios superiores).

- Ideología: votan más los de izquierda $(94,1 \%)$ y derecha $(95,8 \%)$, que los de centro $(87,6 \%)$.

- Estatus socioeconómico: se vota más conforme se asciende en la escala social ( $85 \%$ los obreros no cualificados; $94 \%$ las clases altas o medio/altas).

En el resto de categorías analizadas (sexo, hábitat rural/urbano) no se obtienen diferencias significativas.

Las otras dos vías tradicionales de participación de manera institucional en la política son de formar parte un partido político o un sindicato. Los barómetros del CIS constatan una baja afiliación a estos dos ámbitos en la actualidad. Así, por ejemplo, el barómetro de diciembre de 2019 concluye que un 2,2\% de los españoles mayores de 18 años pertenece (activamente o no) a un partido político y un 6,4\% a sindicatos (habiendo bajado un punto en ambos casos desde 2017). bitos:

Respecto a las relaciones con otras variables, se evidencian diferencias significativas en los siguientes ám-

- Por sexo: los hombres participan en partidos políticos $(2,6 \%)$ y en sindicatos $(7,9 \%)$ más que las mujeres $(1,9 \%$ y $4,9 \%)$.

- Por edad: son las edades intermedias las que participan en mayor medida en partidos $(2,6 \%)$ y sindicatos $(8,9 \%)$.

\footnotetext{
El barómetro del CIS establece seis categorías: Sin estudios, Estudios primarios, Secundarios (1 ${ }^{\mathrm{a}}$ etapa), Secundarios (2 $2^{\mathrm{a}}$ etapa), FP y Estudios superiores. Para este análisis, se han reconvertido en cuatro categorías: Sin estudios, Estudios primarios, Secundarios y Estudios superiores.

20 El barómetro del CIS establece una escala entre "1" (extrema izquierda) y "10" (extrema derecha". Para facilitar los cálculos, se han reagrupado esos valores en tres categorías: Izquierda (de "1" a "3"), Centro (de “4” a "6") y Derecha (de “7” a "10").
} 
- Por nivel de estudios ${ }^{21}$ : conforme se eleva el nivel educativo sube la participación en los partidos políticos; las personas con estudios superiores alcanzan el 4,1\%. Algo similar sucede con la pertenencia a sindicatos, donde los que no alcanzan la primaria no participan, entre los universitarios participa un $11 \%$ y los que tienen secundaria, un $8,4 \%$.

- Por ideología: la participación en partidos es muy baja en todas las categorías, y se encuentran diferencias en cuanto a la participación en los sindicatos: las personas de izquierda participan más $(11,1 \%)$ que las de derechas $(2,3 \%)$.

- Por estatus socioeconómico ${ }^{22}$ : respecto a los partidos políticos participan más las personas pertenecientes a una categoría socioeconómica alta o medio-alta (2,9\%). La clase baja o pobre llega al 1,4\%. En lo que respecta a los sindicatos, no participa nada la clase baja o pobre, mientras que los mayores niveles de participación se producen en las clases media-baja $(7,4 \%)$ y en las clases altas o medio altas $(7,3 \%)$.

A continuación se analizan otras mediaciones de la participación política. Como se ha comentado anteriormente, la participación sociopolítica se puede ejercer directamente o a través de algunas mediaciones. Unas de ellas son los sindicatos y los partidos políticos. Sin embargo, en la sociedad actual, el entramado formado por el tejido asociativo se ha constituido en un elemento clave para la participación institucional a través de los órganos y procesos (Parés, 2009). Además, este tipo de activismo social muchas veces es cauce para la participación no institucional, en manifestaciones, huelgas, etc.; por ello, han sido tratados en este lugar del artículo, como puente entre lo institucional y lo no institucional.

Según los barómetros del CIS de los últimos años, los niveles de participación de los españoles en algún ámbito del asociacionismo son los siguientes:

Tabla 6. Participación en diferentes ámbitos asociativos. Varios años

\begin{tabular}{|l|c|c|c|c|}
\hline Ámbito & $\mathbf{2 0 1 5}$ & $\mathbf{2 0 1 6}$ & $\mathbf{2 0 1 7}$ & $\mathbf{2 0 1 9}$ \\
\hline Colegio profesional & $5,7 \%$ & $4,9 \%$ & $4,3 \%$ & $2,9 \%$ \\
\hline Parroquia / Asoc. religiosa & $7,1 \%$ & $7,7 \%$ & --- & $2,2 \%$ \\
\hline Entidad deportiva & $12,8 \%$ & $12,1 \%$ & $11,3 \%$ & $9,2 \%$ \\
\hline Asociación cultural, Ocio & $13,2 \%$ & $12,8 \%$ & $11,3 \%$ & $6,7 \%$ \\
\hline Asociación social & $9,0 \%$ & $10,7 \%$ & $15,0 \%$ & $9,1 \%$ \\
\hline Asociación juvenil & $3,0 \%$ & $3,2 \%$ & $1,9 \%$ & $1,6 \%$ \\
\hline Asociación voluntaria & $8,5 \%$ & $8,8 \%$ & $9,7 \%$ & -- \\
\hline
\end{tabular}

Fuente: barómetros del CIS de octubre, 2015; octubre, 2016; noviembre, 2017; diciembre, 2019.

La tendencia, en este caso, varía en función del tipo de entidad de la que se trate hasta 2017. Se observa un incremento de la misma respecto de las asociaciones sociales y de acción voluntaria, mientras que el resto experimenta leves descensos (excepto en las asociaciones juveniles). Sin embargo, entre 2017 y 2019 se produce un descenso generalizado en los niveles de participación en todas las asociaciones.

En este caso, también se observan diferencias si se atiende a las variables sociodemográficas y socioeconómicas vistas anteriormente, y en referencia, en exclusiva, al barómetro del 2019, cabe subrayar:

- Por sexo: los hombres participan en mayor medida que las mujeres en las asociaciones juveniles y en las deportivas. Las mujeres participan en mayor medida que los hombres en asociaciones religiosas y sociales.

- Por edad: en general, son los que tienen entre 31 y 64 años los que en mayor medida participan en los ámbitos analizados, con las siguientes excepciones: en las asociaciones juveniles son los menores de 30 años los que más participan, y en las religiosas, son los mayores de 65 años. En las deportivas existe una alta participación de menores de 65 años, incluyendo al grupo más joven.

- Por nivel de estudios: conforme se eleva el nivel educativo aumenta la participación en los diferentes ámbitos analizados.

- Por ideología: hay una tendencia generalizada a que las personas de izquierdas participen más en todo tipo de asociaciones, excepto en las religiosas, que participan más las personas de derechas.

- Por estatus socioeconómico: conforme se eleva el estatus se incrementa la participación en los diferentes ámbitos analizados.

\footnotetext{
El barómetro del CIS de diciembre de 2019 establece 16 categorías o niveles de estudios. Se ha procedido a recodificar esa variable con el fin de hacerla comparable con el barómetro de 2016.

22 En este caso también se han cambiado los valores de la variable respecto del barómetro de 2016, y ha quedado de la siguiente manera: Clase alta y media alta; Clase media-media; Clase media-baja; Clase trabajadora/obrera/proletariado y Clase baja/pobre.
} 
- Respecto a la dimensión rural/urbano ${ }^{23}$ : se observa una tendencia a que se den mayores niveles de participación en las localidades más grandes. Sin embargo, esta tendencia general contempla dos excepciones: en el caso de participar en asociaciones voluntarias no existen diferencias significativas por tamaño del municipio; y, por otra parte, es en las localidades más pequeñas (menos de 2000 habitantes) en las que se da un mayor nivel de pertenencia a un grupo cultural o de ocio.

Para terminar, se abordará el análisis de las vías no institucionales de participación, que son aquellas actuaciones que se producen al margen del impulso de la administración u otras instituciones (es decir, son por irrupción y no por invitación).

De hecho, aunque la mayoría están reguladas por el ordenamiento jurídico y, por lo tanto, son plenamente legales, la práctica totalidad (de las huelgas) o la gran mayoría (manifestaciones) se convocan precisamente para alterar el normal funcionamiento de los cauces reglados de interacción entre la esfera política y otros agentes sociales, por lo que son vistas como una interrupción y, en cierto sentido, como una anomalía.

En este caso, para comprobar la incidencia de determinados procesos políticos y económicos, se presentan los datos relativos a 2012, a 2015, 2016 y $2018^{24}$.

Tabla 7. Participación a través de diversos mecanismos. España

\begin{tabular}{|c|c|c|c|c|c|c|}
\hline ¿Ha participado durante el último año? & $04 / 2012$ & $04 / 2014$ & $10 / 2015$ & $10 / 2016$ & $04 / 2018$ & $12 / 2019^{25}$ \\
\hline ¿... en alguna manifestación? & $21,2 \%$ & $18,4 \%$ & $13,1 \%$ & $12,0 \%$ & $22,4 \%$ & $19,9 \%$ \\
\hline ¿... en alguna huelga? & $18,8 \%$ & $12,4 \%$ & $7,0 \%$ & $5,3 \%$ & $14,2 \%$ & $11,1 \%$ \\
\hline ¿... en algún foro o blog político? & $5,4 \%$ & $5,4 \%$ & $4,6 \%$ & $4,7 \%$ & $5,5 \%$ & --- \\
\hline ¿... en alguna petición de firmas? & $22,0 \%$ & $30,6 \%$ & $25,8 \%$ & $25,6 \%$ & $31,1 \%$ & $12,9 \%$ \\
\hline
\end{tabular}

Fuente: barómetros del CIS; abril 2012 y 2014, octubre 2015 y 2016, abril de 2018, diciembre de 2019.

Puede comprobarse cómo en el primer año analizado se deja sentir el efecto del 15M, así como el resto de movimientos que vieron la luz después de él (Mareas, etc.). Posteriormente, se produce un decrecimiento de las movilizaciones en los años 2015 y 2016. Finalmente, en 2018 se percibe el impacto del proceso catalán y de las movilizaciones que surgieron a partir de él (a favor y en contra), tanto dentro como fuera de Cataluña. En 2019 desciende la participación en huelgas y manifestaciones, pero se sigue manteniendo en valores cercanos al año anterior.

Quizás, la única dimensión que no se corresponde con la evolución de los acontecimientos presentados es la referente a la "petición de firmas". No obstante, cabe destacar en los últimos años la incidencia de la puesta en marcha de campañas de recogida de firmas a través de canales online ${ }^{26}$.

Se presentan a continuación las diferencias observadas atendiendo a las variables sociodemográficas, y se pone la atención en los dos últimos barómetros, el de 2019 (huelgas y manifestaciones) y el de 2018 (respecto de blogs y petición de firmas):

- Por sexo: los hombres participan ligeramente más a través de huelgas, manifestaciones y petición de firmas, y las mujeres lo hacen más a través de blogs o foros.

- Por edad: son los jóvenes (menores de 30 años) los que en mayor medida participan en huelgas $(22,4 \%)$, manifestaciones $(30,3 \%)$, blogs $(10,6 \%)$ y petición de firmas $(42 \%)$. Estos datos son, para las personas entre 30 y 64 años: $12 \%, 21,5 \%, 6 \%$ y $36 \%$. Mientras que para los mayores de 65 años desciende drásticamente a los siguientes valores: $2,6 \%, 10,5 \%, 1 \%$ y $14 \%$.

- Por nivel de estudios: en todos los ítems analizados, se observa una clara línea ascendente en el porcentaje de participación conforme aumenta el nivel educativo. Así, por ejemplo, respecto a la participación en manifestaciones, encontramos la siguiente evolución: sin estudios $(4,4 \%)$, estudios primarios $(10,8 \%)$, estudios secundarios (24\%) y estudios superiores $(33 \%)$.

- Por ideología: son las personas de izquierda, dentro de la escala ideológica, las que más participan a través de las vías comentadas. Las diferencias se observan especialmente en lo que hace referencia a la asistencia a huelgas y manifestaciones: $25 \%$ y $41,5 \%$ para los de izquierdas y $2,3 \%$ y $7 \%$ para los de derechas.

\footnotetext{
En este caso, los análisis se hacen con el barómetro de noviembre de 2017.

24 Se deja de lado en el análisis algunas de las vías no institucionales de participación, centrándose en aquellas de las que se dispone de datos en los barómetros del CIS.

25 En el año 2019 cambiaron algunas preguntas: ya no se hizo la del foro o blog, y la de "Participar en alguna petición de firmas" se cambió por "Firmar una petición/recogida de firmas". Por eso no realizamos la comparabilidad de ese dato respecto a los anteriores años.

26 Este es el caso, por ejemplo, de Change.org, que en 2018 alcanzó los 265.786.771 usuarios y logró 603.903 .062 de firmas en todo el mundo.
} 
- Por estatus socioeconómico: no se encuentra una diferencia estadísticamente significativa. Lo que se puede resaltar es que la clase baja o pobre se comporta con unos niveles de participación más bajos que el resto en todos los ámbitos.

- Respecto a la dimensión rural/urbano, en 2018 se detectó que se participa más conforme aumenta el tamaño del municipio. Así, por ejemplo, el 8,4\% de las personas residentes en pueblos de menos de 2000 habitantes había asistido a una huelga en los últimos doce meses, el 13\% a una manifestación o el 20\% había participado en una petición de firmas. Esos mismos valores para los residentes en municipios de más de un millón de habitantes son: $17 \%, 32 \%$ y $43 \%$, respectivamente.

\section{Hacia la construcción de una tipología sobre el comportamiento participativo}

El siguiente paso analítico que se propone consiste en establecer una tipología de ciudadanos en función de su comportamiento participativo. Para ello, se va a recurrir al último de los barómetros del CIS en el que se abordan de forma conjunta todas las cuestiones analizadas: el de octubre de 2016.

Teniendo en cuenta todas las vías de participación vistas anteriormente, se pueden identificar dos grandes grupos de ciudadanos, cada uno de ellos con una subdivisión en su interior:

- Aquellas personas que no participan a través de ningún tipo de espacio o mediación de entre los descritos anteriormente: $39,1 \%$

o Y que tampoco vota: $8,4 \%$ de la población.

o Y que sí que vota: $30,7 \%$ de la población.

- De entre las personas que sí que participan a través de algún tipo de espacio o mediación (60,9\%), se distingue, a su vez, entre:

o Aquellas personas que participan a través de las vías tradicionales, es decir, partidos y/o sindicatos: $10,9 \%$ de la población.

o Aquellas personas que participan en algún tipo de asociación de las contempladas más arriba (colegios profesionales, parroquia o asociación religiosa, entidades deportivas, asociaciones culturales o de ocio, asociaciones sociales, asociaciones juveniles, asociaciones voluntarias): $34,9 \%$ de la población.

o Aquellas personas que participan en alguna de las actividades contempladas en las vías no institucionales de participación (manifestación, huelga, foro o blog político, petición de firmas): 46,3\% de la población.

En este último gran grupo se encuentra un volumen de personas que sí que fue a votar $(53,8 \%)$, mientras que el resto no fue a votar $(7,1 \%)$.

Vistos estos datos desde otra perspectiva, entre los no votantes ( $15,5 \%$ de la población), se pueden identificar dos grupos: los que participan a través de otras vías (7,1\% de la población; es decir, el 45,8\% de los no votantes) y los que no participan en nada (el 8,4\%; es decir, el 54,2\% de los no votantes).

Esto quiere decir que se observa una fuerte correlación entre el voto y el hecho de participar en otros ámbitos participativos, ya que no vota el $21,5 \%$ de los que no participan a través de ninguna otra vía, mientras que solo deja de votar el $11,7 \%$ de los que sí participan. Y también es cierto que existe un abstencionista que participa en actividades políticas no electorales. Estas conclusiones permiten confirmar lo que ya han puesto de manifiesto otros recientes estudios para el conjunto de países europeos (Portos et al., 2019).

Teniendo en cuenta todas las posibilidades que se abren ante la participación, se puede construir la tipología presentada en la Figura 1).

Antes de proceder al análisis de las características de estos grupos, merece la pena resaltar que hay un 5\% de la población que lleva a cabo una participación en todos y cada uno de los ámbitos analizados. Además, se producen situaciones variadas e híbridas, con gente que participa en partidos, sindicatos y asociaciones $(1,9 \%)$ o utiliza vías informales $(2,2 \%)$. Además, los hay que, junto con las vías informales, pertenecen a asociaciones $(17,1 \%)^{27}$. Y en todos los casos, hay algún grupo de personas en estos colectivos que no vota (por ejemplo, no acude a votar un $8,8 \%$ de la población que lleva a cabo una participación en todos y cada uno de los ámbitos analizados).

Finalmente, aparecen las personas que solo utilizan o participan en uno de los mecanismos o ámbitos descritos: partidos políticos y/o sindicatos $(1,8 \%)$, asociaciones (10,9\%) o vías informales $(22 \%)$.

En este sentido, lo más destacable es comprobar que si una persona participa en un partido político o sindicato, es casi seguro (en el 83,5\% de los casos) que lo hará en otra mediación o espacio. 
Figura 1. Tipología de ciudadanos en torno a su comportamiento participativo (\%)

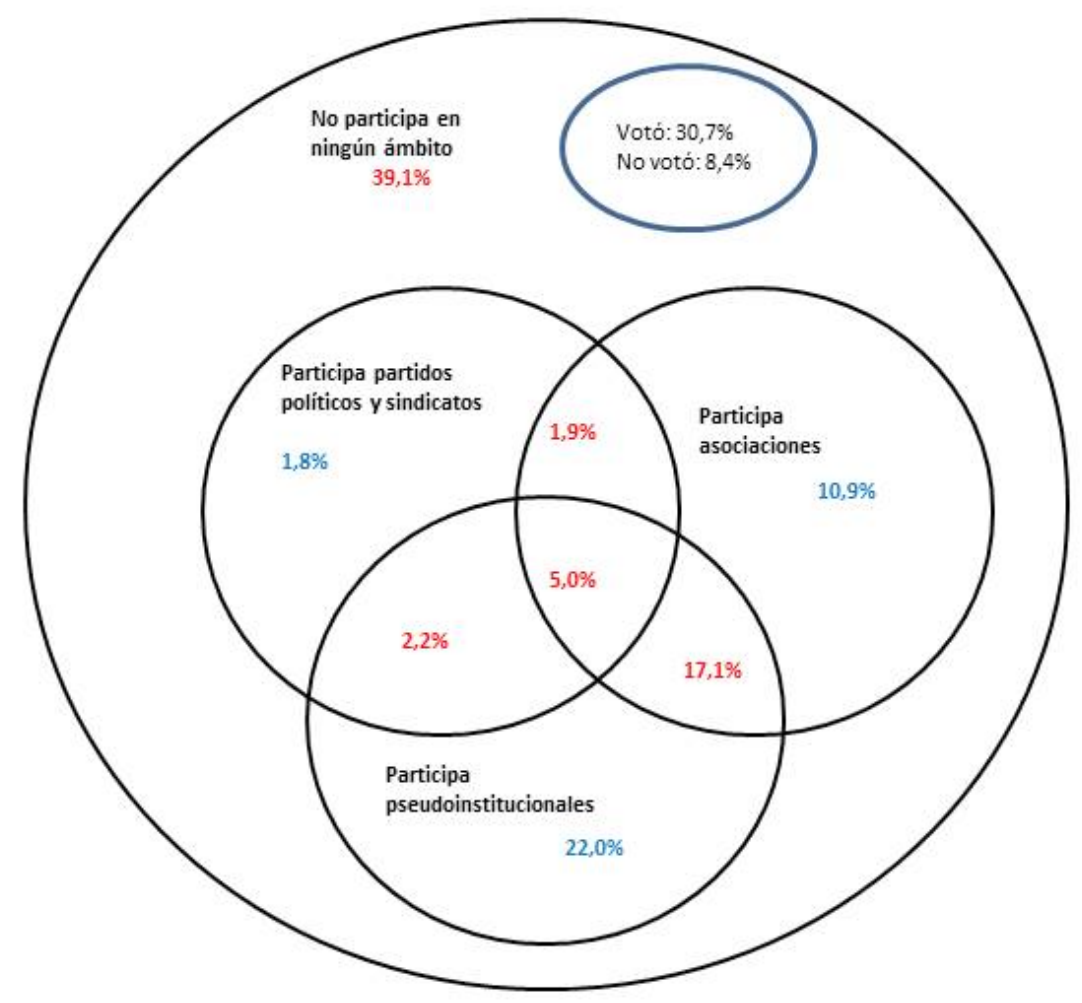

Fuente: elaboración propia a partir del barómetro del CIS, octubre 2016.

Y, a continuación, se van a presentar los datos de la figura anterior, pero esta vez en valores absolutos, con el fin de poder dimensionar el volumen de personas que pertenece a cada categoría de la tipología (sobre mayores de 18 años):

Figura 2. Tipología de ciudadanos en torno a su comportamiento participativo (valores absolutos)

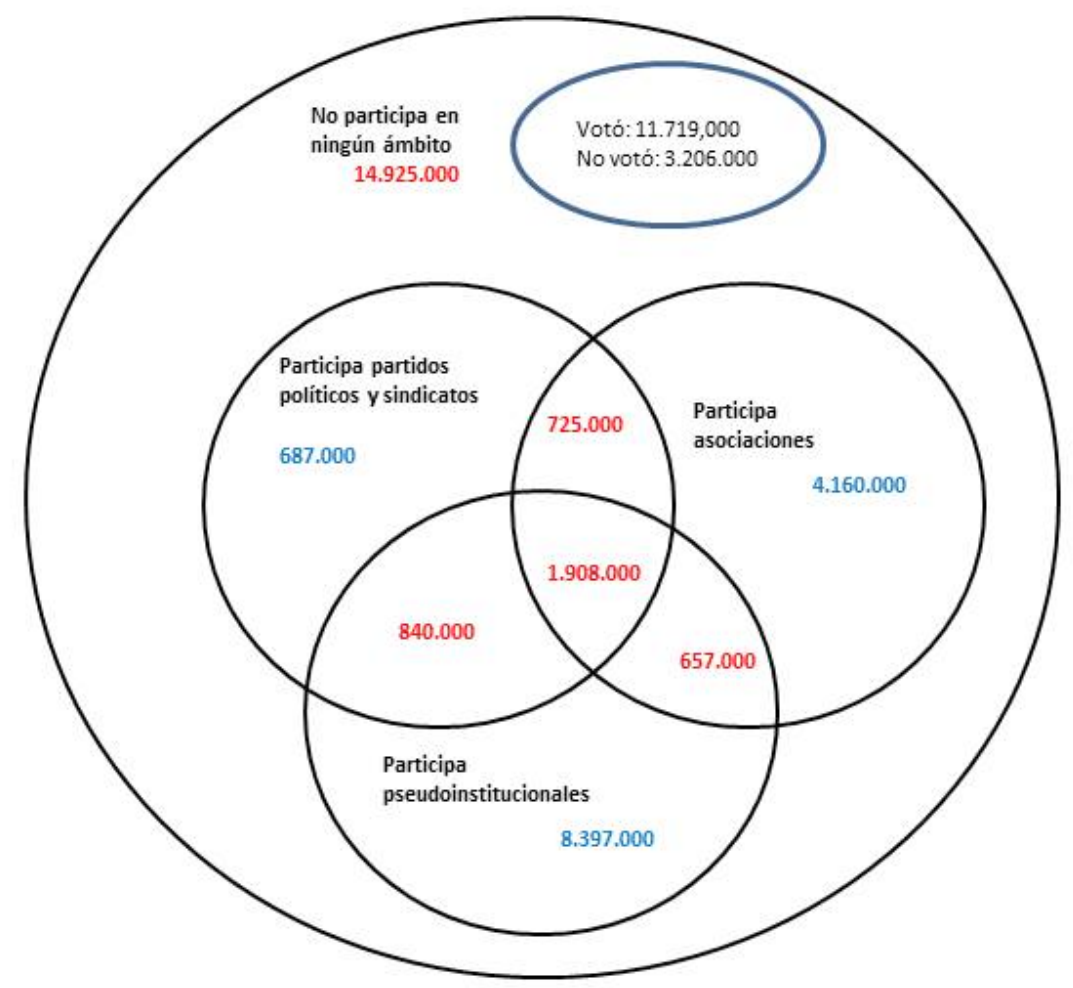

Fuente: elaboración propia a partir del barómetro del CIS, octubre 2016. 
Si se toma en su conjunto toda la información vista hasta el momento y se da un paso argumentativo más, se puede establecer un contínuum que va desde el voto y la participación en partidos políticos y sindicatos (que demuestra una confianza en el sistema representativo), pasando por la participación en asociaciones (que indica la apuesta por estrategias más deliberativas, de un lado, o menos institucionales, de otro), hasta la participación en actividades informales o pseudoinstitucionales. Lo que se va a hacer es comprobar si las variables estudiadas anteriormente inciden en el hecho de participar en cada uno de esos ámbitos:

Tabla 8. Participación electoral. Elecciones Generales de 2016.

Porcentaje de personas que fue a votar y votó vs. Tipología participativa

\begin{tabular}{|l|c|c|c|c|c|}
\hline Pregunta & Toda población & $\begin{array}{c}\text { No han participado } \\
\text { en NADA }\end{array}$ & $\begin{array}{c}\text { Han participado } \\
\text { en partidos y } \\
\text { sindicatos }\end{array}$ & $\begin{array}{c}\text { Han } \\
\text { participado } \\
\text { en } \\
\text { asociaciones }\end{array}$ & $\begin{array}{c}\text { Han } \\
\text { participado } \\
\text { por vías } \\
\text { informales }\end{array}$ \\
\hline Votó & $\mathbf{8 4 , 5 \%}$ & $78,5 \%$ & $91,5 \%$ & $89,0 \%$ & $88,7 \%$ \\
\hline
\end{tabular}

Fuente: barómetro, CIS: octubre, 2016.

Como se ha comentado anteriormente, los datos indican que participar en algún ámbito o a través de alguna de las vías analizadas implica un mayor nivel de participación en las elecciones generales; como mínimo, 10 puntos por encima de las personas que no participan en nada.

Tabla 9. Grado de entendimiento de la política vs. Tipología participativa

\begin{tabular}{|l|c|c|c|c|c|c|}
\hline & $\begin{array}{c}\text { Toda } \\
\text { población }\end{array}$ & $\begin{array}{c}\text { No han } \\
\text { participado en } \\
\text { nada } \\
\text { y no votó }\end{array}$ & $\begin{array}{c}\text { No han } \\
\text { participado } \\
\text { en nada } \\
\text { y votó }\end{array}$ & $\begin{array}{c}\text { Han } \\
\text { participado } \\
\text { en partidos y } \\
\text { sindicatos }\end{array}$ & $\begin{array}{c}\text { Han } \\
\text { participado } \\
\text { en } \\
\text { asociaciones }\end{array}$ & $\begin{array}{c}\text { Han } \\
\text { participado } \\
\text { por vías } \\
\text { informales }\end{array}$ \\
\hline Entiende y no es complicada & $40,9 \%$ & $15,7 \%$ & $25,3 \%$ & $60,3 \%$ & $56,7 \%$ & $54,9 \%$ \\
\hline Indecisión & $24,9 \%$ & $20,5 \%$ & $23,6 \%$ & $21,3 \%$ & $18,5 \%$ & $22,6 \%$ \\
\hline No entiende y es complicada & $34,2 \%$ & $56,0 \%$ & $47,9 \%$ & $18,4 \%$ & $24,8 \%$ & $22,5 \%$ \\
\hline
\end{tabular}

Fuente: barómetro, CIS: octubre, 2016.

En todos los casos se encuentran diferencias significativas estadísticamente, en la dirección de que la comprensión de la política está asociada con el grado de participación en todos los ámbitos señalados:

Tabla 10. Podría decirme qué importancia tienen en su vida los siguientes aspectos (media de 1 a 10) vs.

Tipología participativa

\begin{tabular}{|l|c|c|c|c|c|c|}
\hline & $\begin{array}{c}\text { Toda } \\
\text { población }\end{array}$ & $\begin{array}{c}\text { No han } \\
\text { participado en } \\
\text { nada } \\
\text { no votó }\end{array}$ & $\begin{array}{c}\text { No han } \\
\text { participado en } \\
\text { nada } \\
\text { y votó }\end{array}$ & $\begin{array}{c}\text { Han } \\
\text { participado } \\
\text { en partidos y } \\
\text { sindicatos }\end{array}$ & $\begin{array}{c}\text { Han } \\
\text { participado } \\
\text { en asociaciones }\end{array}$ & $\begin{array}{c}\text { Han } \\
\text { participado } \\
\text { por vías } \\
\text { informales }\end{array}$ \\
\hline La familia & 9,69 & 9,64 & 9,72 & 9,62 & 9,69 & 9,67 \\
\hline Los/as amigos/as & 8,21 & 7,97 & 8,00 & 8,30 & 8,48 & 8,33 \\
\hline El tiempo libre & 7,95 & 7,70 & 7,65 & 8,16 & 8,25 & 8,10 \\
\hline La política & $\mathbf{4 , 6 4}$ & $\mathbf{2 , 7 5}$ & $\mathbf{4 , 1 7}$ & $\mathbf{5 , 6 3}$ & $\mathbf{5 , 1 4}$ & $\mathbf{5 , 3 1}$ \\
\hline EI trabajo & 8,66 & 8,47 & 8,49 & 8,89 & 8,65 & 8,79 \\
\hline La religión & 4,25 & 4,11 & 4,75 & 3,73 & 4,39 & 3,57 \\
\hline Asociaciones, clubes y... & $\mathbf{5 , 0 2}$ & $\mathbf{3 , 9 4}$ & $\mathbf{4 , 1 7}$ & $\mathbf{5 , 6 7}$ & $\mathbf{5 , 9 4}$ & $\mathbf{5 , 6 0}$ \\
\hline
\end{tabular}

Fuente: barómetro, CIS: octubre, 2016.

Es necesario resaltar el hecho de que es precisamente en los dos ámbitos más vinculados con la participación, en los que se encuentran diferencias entre los grupos. Así, las personas que no han participado en nada presentan menos valores respecto a la importancia que en sus vidas tiene la política y en las asociaciones, clubes y otras actividades asociativas, en las que se da un punto de diferencia entre los dos grupos.

Por otra parte, las personas que participan en partidos y sindicatos son los que tienen valores más altos respecto a la importancia que le confieren a la política. Y las personas que participan en asociaciones, las que más alto puntúan en la importancia de las asociaciones, clubes y otras actividades asociativas. 
Tabla 11. El voto es la única forma en que la gente como Ud. puede influir en lo que hace el Gobierno vs. Tipología participativa

\begin{tabular}{|l|c|c|c|c|c|c|}
\hline & $\begin{array}{c}\text { Toda } \\
\text { población }\end{array}$ & $\begin{array}{c}\text { No han } \\
\text { participado en } \\
\text { nada } \\
\text { y no votó }\end{array}$ & $\begin{array}{c}\text { No han } \\
\text { participado } \\
\text { en nada } \\
\text { y votó }\end{array}$ & $\begin{array}{c}\text { Han } \\
\text { participado } \\
\text { en partidos y } \\
\text { sindicatos }\end{array}$ & $\begin{array}{c}\text { Han } \\
\text { participado } \\
\text { en } \\
\text { asociaciones }\end{array}$ & $\begin{array}{c}\text { Han } \\
\text { participado } \\
\text { por vías } \\
\text { informales }\end{array}$ \\
\hline De acuerdo & $57,4 \%$ & $44,0 \%$ & $65,7 \%$ & $61,0 \%$ & $53,1 \%$ & $53,2 \%$ \\
\hline $\begin{array}{l}\text { Ni de acuerdo } \mathbf{~ n i ~} \\
\text { en desacuerdo }\end{array}$ & $7,5 \%$ & $11,4 \%$ & $8,0 \%$ & $5,9 \%$ & $6,8 \%$ & $6,8 \%$ \\
\hline En desacuerdo & $30,8 \%$ & $33,7 \%$ & $20,5 \%$ & $31,3 \%$ & $37,4 \%$ & $38,5 \%$ \\
\hline
\end{tabular}

Fuente: barómetro, CIS: octubre, 2016.

No se encuentra una asociación significativa estadísticamente entre estar de acuerdo con la afirmación "El voto es la única forma en la que la gente puede influir en lo que hace el Gobierno" y la participación en partidos o en sindicatos. En el resto de casos, sí que se da esa significatividad en la asociación. Entre aquellos que han participado en asociaciones o a través de otras vías informales, se encuentra un mayor rechazo a esta afirmación, con lo que se abre la puerta a otras vías para influir en lo que hace el Gobierno. Pero son de la misma opinión los que no participan en nada y no votan.

Tabla 12. Es mejor no meterse en política vs. Tipología participativa

\begin{tabular}{|l|c|c|c|c|c|c|}
\hline & $\begin{array}{c}\text { Toda } \\
\text { población }\end{array}$ & $\begin{array}{c}\text { No han } \\
\text { participado en } \\
\text { nada } \\
\text { y no votó }\end{array}$ & $\begin{array}{c}\text { No han } \\
\text { participado } \\
\text { en nada } \\
\text { y votó }\end{array}$ & $\begin{array}{c}\text { Han } \\
\text { participado } \\
\text { en partidos y } \\
\text { sindicatos }\end{array}$ & $\begin{array}{c}\text { Han } \\
\text { participado } \\
\text { en } \\
\text { asociaciones }\end{array}$ & $\begin{array}{c}\text { Han } \\
\text { participado } \\
\text { por vías } \\
\text { informales }\end{array}$ \\
\hline De acuerdo & $43,7 \%$ & $52,4 \%$ & $53,5 \%$ & $28,7 \%$ & $32,9 \%$ & $30,1 \%$ \\
\hline $\begin{array}{l}\text { Ni de acuerdo ni } \\
\text { en desacuerdo }\end{array}$ & $13,8 \%$ & $13,9 \%$ & $16,4 \%$ & $8,8 \%$ & $12,5 \%$ & $13,1 \%$ \\
\hline En desacuerdo & $35,8 \%$ & $21,1 \%$ & $24,6 \%$ & $59,9 \%$ & $52,2 \%$ & $53,9 \%$ \\
\hline
\end{tabular}

Fuente: barómetro, CIS: octubre, 2016.

En este caso la gran fractura se encuentra entre quienes no han participado en nada (voten o no voten) y el resto de personas que sí ha participado en algún espacio, ámbito o vía (para los cuales, la mayoría está en contra de esta frase).

No es preceptivo seguir con el análisis del grado de participación de estos colectivos en los diferentes espacios y ámbitos, ya que en este caso sí que las diferencias son notables, puesto que precisamente la tipología ha sido construida en función de esas variables.

Lo que sí que resulta interesante es observar las diferencias entre esos dos grupos atendiendo a las variables sociodemográficas que han sido utilizadas a la largo del artículo:

Tabla 13. Participación (sí/no en Tipología participativa) en función de algunas variables. España (\%)

\begin{tabular}{|c|c|c|c|c|c|c|}
\hline & $\begin{array}{c}\text { Toda } \\
\text { población }\end{array}$ & $\begin{array}{c}\text { No han } \\
\text { participado en } \\
\text { nada } \\
\text { y no votó }\end{array}$ & $\begin{array}{c}\text { No han } \\
\text { participado en } \\
\text { nada } \\
\text { y votó }\end{array}$ & $\begin{array}{c}\text { Han participado } \\
\text { en partidos y } \\
\text { sindicatos }\end{array}$ & $\begin{array}{l}\text { Han participado } \\
\text { en asociaciones }\end{array}$ & $\begin{array}{c}\text { Han participado } \\
\text { por vías } \\
\text { informales }\end{array}$ \\
\hline Hombres & $48,4 \%$ & $52,4 \%$ & $47,0 \%$ & $56,6 \%$ & $50,6 \%$ & $48,1 \%$ \\
\hline Mujeres & $51,6 \%$ & $47,6 \%$ & $53,0 \%$ & $43,4 \%$ & $49,4 \%$ & $51,9 \%$ \\
\hline De 18 a 30 años & $14,5 \%$ & $24,7 \%$ & $11,1 \%$ & $5,5 \%$ & $14,0 \%$ & $16,3 \%$ \\
\hline De 31 a 64 años & $61,3 \%$ & $54,8 \%$ & $52,4 \%$ & $81,3 \%$ & $64,1 \%$ & $70,3 \%$ \\
\hline De 65 o más años & $24,2 \%$ & $20,5 \%$ & $36,5 \%$ & $13,2 \%$ & $21,8 \%$ & $13,4 \%$ \\
\hline Izquierda & $32,2 \%$ & $19,8 \%$ & $24,0 \%$ & $41,3 \%$ & $33,4 \%$ & $42,4 \%$ \\
\hline Centro & $49,9 \%$ & $70,8 \%$ & $53,9 \%$ & $43,7 \%$ & $47,9 \%$ & $44,4 \%$ \\
\hline Derecha & $17,9 \%$ & $9,4 \%$ & $22,1 \%$ & $15,1 \%$ & $18,7 \%$ & $13,2 \%$ \\
\hline Sin Estudios & $4,7 \%$ & $9,0 \%$ & $8,8 \%$ & $1,5 \%$ & $1,6 \%$ & $1,8 \%$ \\
\hline Primarios & $18,1 \%$ & $22,9 \%$ & $27,4 \%$ & $9,2 \%$ & $12,9 \%$ & $9,2 \%$ \\
\hline
\end{tabular}




\begin{tabular}{|c|c|c|c|c|c|c|}
\hline & $\begin{array}{c}\text { Toda } \\
\text { población }\end{array}$ & $\begin{array}{c}\text { No han } \\
\text { participado en } \\
\text { nada } \\
\text { y no votó } \\
\end{array}$ & $\begin{array}{c}\text { No han } \\
\text { participado en } \\
\text { nada } \\
\text { y votó }\end{array}$ & $\begin{array}{c}\text { Han participado } \\
\text { en partidos y } \\
\text { sindicatos }\end{array}$ & $\begin{array}{l}\text { Han participado } \\
\text { en asociaciones }\end{array}$ & $\begin{array}{c}\text { Han participado } \\
\text { por vías } \\
\text { informales }\end{array}$ \\
\hline Secundarios & $56,1 \%$ & $62,0 \%$ & $53,7 \%$ & $59,8 \%$ & $50,1 \%$ & $59,2 \%$ \\
\hline $\begin{array}{l}\text { Estudios } \\
\text { Superiores }\end{array}$ & $21,1 \%$ & $6,0 \%$ & $10,1 \%$ & $29,5 \%$ & $35,4 \%$ & $29,8 \%$ \\
\hline $\begin{array}{l}\text { Clase alta/media- } \\
\text { alta }\end{array}$ & $19,0 \%$ & $5,6 \%$ & $8,7 \%$ & $24,2 \%$ & $31,0 \%$ & $27,6 \%$ \\
\hline $\begin{array}{l}\text { Nuevas clases } \\
\text { medias }\end{array}$ & $23,0 \%$ & $21,1 \%$ & $20,4 \%$ & $29,0 \%$ & $22,9 \%$ & $24,7 \%$ \\
\hline $\begin{array}{l}\text { Viejas clases } \\
\text { medias }\end{array}$ & $14,2 \%$ & $13,0 \%$ & $17,6 \%$ & $14,9 \%$ & $14,4 \%$ & $10,9 \%$ \\
\hline $\begin{array}{l}\text { Obreros/as } \\
\text { cualificados/as }\end{array}$ & $29,3 \%$ & $40,4 \%$ & $35,4 \%$ & $21,2 \%$ & $21,4 \%$ & $25,7 \%$ \\
\hline $\begin{array}{l}\text { Obreros/as no } \\
\text { cualificados }\end{array}$ & $14,5 \%$ & $19,9 \%$ & $17,9 \%$ & $10,8 \%$ & $10,4 \%$ & $11,1 \%$ \\
\hline Menos 2000 h. & $7,3 \%$ & $2,4 \%$ & $8,6 \%$ & $11,0 \%$ & $7,8 \%$ & $6,5 \%$ \\
\hline $\begin{array}{l}\text { Entre } 2001 \text { y } \\
40000 \text { h. }\end{array}$ & $75,1 \%$ & $86,7 \%$ & $77,0 \%$ & $71,3 \%$ & $71,3 \%$ & $72,8 \%$ \\
\hline Más de 40000 h. & $17,6 \%$ & $10,8 \%$ & $14,4 \%$ & $17,6 \%$ & $20,9 \%$ & $20,7 \%$ \\
\hline
\end{tabular}

Fuente: barómetro, CIS: octubre, 2016.

Como en los casos anteriores, se van a tratar de establecer los rasgos distintivos de los perfiles de los diferentes grupos analizados, atendiendo a una serie de variables sociodemográficas:

- La dimensión rural/urbano:

o Se percibe un incremento de la presencia de las ciudades más populosas conforme nos desplazamos desde la visión más tradicional de la participación a la menos institucional.

- El sexo:

o No se encuentra significatividad estadística.

- La edad:

o En general, los niveles de participación suben en las edades maduras (entre 31 y 64 años) y bajan en la adulta (más de 64 años).

o Esta tendencia se ve incrementada en el caso de la participación en partidos políticos y/o sindicatos.

- $\quad$ La autoubicación ideológica:

o Existe una mayor tendencia a la participación entre las personas que se ubican en la izquierda del arco ideológico.

- Nivel educativo:

o Hay una mayor presencia de personas con estudios superiores entre el colectivo que sí que participa (y menor presencia de personas sin estudios o con estudios primarios).

- Categoría socioeconómica:

o Las clases altas y medio altas presentan unos mayores niveles de participación, especialmente a través del asociacionismo.

- También presentan altos niveles de participación en partidos políticos y/o sindicatos las nuevas clases medias.

\section{Conclusiones}

Este artículo ha analizado las percepciones y comportamientos de la ciudadanía en torno a su cercanía o alejamiento respecto de los planteamientos que requieren la democracia representativa y la democracia deliberativa. 
Basándonos principalmente en los barómetros del CIS, se ha podido concluir que existe una elevada diversidad de situaciones que no permiten responder de manera categórica a qué fórmula democrática se adscribe la ciudadanía española. Se puede establecer un contínuum que pone de manifiesto (por los hechos) la confianza en fórmulas propias del sistema representativo, evidenciado por el alto índice de participación en las elecciones. Pero, igualmente, se observa un respaldo a las estrategias de corte más deliberativo, como las que pueden vincularse a la participación en asociaciones, hasta la participación en actividades informales o pseudoinstitucionales.

La derivada más importante es la elaboración de una tipología participativa, a partir de la cual inferir el posicionamiento en torno a los dos tipos de democracia. El elemento clave para establecer la tipología ha sido el no participar a través de los espacios o mediaciones contemplados (partidos y/o sindicatos, asociaciones o vías pseudoinstitucionales). Se ha podido demostrar que existe una primera fractura poblacional entre los que lo hacen y los que no. Los primeros votan en mayor medida, comprenden más la política, piensan que hay más maneras que el voto para influir en política y piensan en menor medida que es mejor no meterse en política. Además, para ellos, la política es más importante en sus vidas, igual que el asociacionismo. A partir de ahí, dentro del grupo de los que no participan en estos ámbitos, se produce una segunda fractura entre los que votan y los que no, ya que estos últimos presentan menor comprensión y menor interés por participar en política que los primeros, además de ser menos importante en sus vidas tanto la política como el asociacionismo.

Quizás la conclusión más sorprendente es que no existe una previsible tercera fractura al interior de los que sí que participaron en algún ámbito, ya que se encuentran valores muy parecidos en todas las variables.

En consecuencia, a partir de la radiografía elaborada, los resultados han constatado en gran medida, pero no totalmente la hipótesis de trabajo: existe un posicionamiento diverso ante las nuevas alternativas, aunque quizás no en tanta medida como se esperaba. Y esas diferencias están relacionadas también solo de forma parcial con algunas variables sociodemográficas, especialmente tamaño de hábitat, autoubicación ideológica, nivel de estudios y clase social. Estas dos últimas constataciones provocan que resurja el debate en torno a si estas fracturas reproducen, e incluso aumentan, viejas desigualdades sociales preexistentes, lo que dificultaría la profundización en la democracia y el incremento de la igualdad que parecieran prometer.

La literatura política coincide en la necesidad de caminar hacia la reforma y fortalecimiento de un modelo democrático más inclusivo que propicie canales que contribuyan al fomento de una ciudanía activa. Sin embargo, el diagnóstico elaborado ha evidenciado que la demanda de profundización democrática no es unánime. Es especialmente crítico para las personas que no participan en nada, por lo que las fórmulas planteadas deberán dar respuesta a una ciudadanía fragmentada que manifiesta diferentes niveles de implicación en la esfera pública, garantizando una mayor capacidad de intervención social.

\section{Bibliografía}

Abal Medina, J. M. (2004): La muerte y la resurrección de la representación política, Buenos Aires, Fondo de Cultura Económica. Beck, U. (1994): La sociedad del riesgo global, Madrid, Siglo XXI.

Braun, D. y S. Hutter (2016): "Political trust, extra-representational participation and the openness of political systems", International Political Science Review, 37(2), pp. 151-165. https://doi.org/10.1177/0192512114559108

Bobbio, N. (1985): "La crisis de la democracia y la lección de los clásicos", en N. Bobbio, G. Pontara y S. Veca, Crisis de la Democracia, Barcelona, Editorial Ariel S.A., pp. 5-25. https://doi.org/10.22201/fcpys.24484903e.1986.2.60044

Brugué, Q. (2010): "Regeneración democrática: un marco para desarrollar el gobierno abierto", Revista Deliberación. Revista para la mejora de la calidad democrática, 3, pp. 21-37.

Carrasco, M. y B. Rodríguez Ruíz (2019): La participación ciudadana como pilar del Estado democrático: posibilidades y límites en el marco de la democracia representativa, Pamplona, Aranzadi.

Casquete, J. (2006): "Manifestaciones e identidad colectiva", Revista Internacional de Sociología, 42, 101-125. doi:10.3989/ ris.2005.i42.198

CIS (2002): Ciudadanía, participación y democracia (Estudio 2450), Madrid, CIS.

Cohen J. L. y A. Arato (2000): Sociedad civil y teoría política, México, Fondo de Cultura Económica.

Colectivo IOÉ (2008): Barómetro Social de España, Análisis del periodo 1994-2006, Madrid, Traficantes de sueños y CIP Ecosocial.

Crozier, M. J., S.P. Huntington y J. Watanuki (1975): The Crisis of Democracy: report on the Governability of Democracies to the Trilateral Commission, New York, University Press.

Dahrendorf, R. (2002): Después de la democracia: Entrevistado por Antonio Polito, Barcelona, Editorial Crítica.

De Marco, S., E. Ganuza, C. Güemes, J. M. Robles y P. García-Espín (2018): Ciudadanos y democracia representativa: ¿una relación conflictiva? Análisis de la desconfianza en las instituciones en España, Madrid, CIS (Colección "Opiniones y Actitudes", Núm. 75).

Dryzek, J. S. (2000): Deliberative Democracy and Beyond, Oxford, Oxford U.P.

Easton, D. (1975): “Are-assessment of the concept of political support”, British Journal of Political Science, 5(4), pp. 435-457. https://doi.org/10.1017/S0007123400008309

Ercan, S. A. y J. P. Gagnon (2014): “The Crisis of Democracy. Which Crisis? Which Democracy?”, Democratic Theory, 1(2), pp. 1-10. https://doi.org/10.3167/dt.2014.010201 
Escobar, M. y P. Cabrera (2021): "Índice de calidad de la democracia”, en A. Penadés y A. Garmendia, dirs., Informe sobre la Democracia en España, 2020. El año de la pandemia, Madrid, Fundación Alternativas, pp. 223-254.

García, I. y A. Novo (2017): "La emergencia del 'consumidor consciente': un análisis de la participación política a través de las decisiones de compra”, Revista Española de Investigaciones Sociológicas, 158, pp. 59-78. (http://dx.doi.org/10.5477/cis/ reis.158.59)

Fernández, G. (Coord.) (2019): VIII Informe FOESSA, Madrid, Fundación FOESSA.

Fernández, J. L. (2018): What do citizens want from participatory democracy?, Tesis doctoral inédita, Universidad de Granada, Granada. http://digibug.ugr.es/bitstream/handle/10481/55424/56828.pdf?sequence=4\&isAllowed=y [Consulta: 20 de octubre de 2020]

Font, J., C. Navarro, M. Wojcieszak y P. Alarcón (2012): ¿"Democracia sigilosa” en España? Preferencias de la ciudadanía española sobre las formas de decisión política y sus factores explicativos, Madrid, CIS (Colección "Opiniones y Actitudes", Núm. 71).

Friedman, M. (1991): “Consumer Boycotts: A Conceptual Framework and Research Agenda”, Journal of Social Issues, 47(1), pp. 149-168. https://doi.org/10.1111/j.1540-4560.1991.tb01817.x

Ganuza, E. y F. Francés (2012): El círculo virtuoso de la democracia: los presupuestos participativos a debate, Madrid, CIS.

Ganuza, E., P. García-Espín y S. De Marco (2017): "Do People want more participation? Tensions and conflicts in governance in times of skepticism", Revista de Estudios Políticos, 176, pp. 253-279. https://doi.org/10.18042/cepc/rep.176.08

García-Espín, P. y M. Jiménez (2017): "Los procesos participativos como potenciadores de la democracia. Explorando los efectos, mecanismos y evidencias en la sociedad civil”, Revista de Estudios Politicos, 177, pp. 113-146. doi: https://doi.org/10.18042/ cepc/rep.177.04

García-Espín, P., E. Ganuza y S. De Marco (2017): “¿Asambleas, referéndums o consultas? Representaciones sociales de la participación ciudadana", Revista Española de Investigaciones Sociológicas, 157, pp. 45-64. http://dx.doi.org/10.5477/cis/ reis. 157.45

Gunther, R. y J. R. Montero (2006): "The multidimensionality of political support for new democracies: conceptual redefinition and empirical refinement”, en M. Torcal y J. R. Montero, Political Desaffection in Contemporany Democracies, London, Routledge, pp.46-78.

Hibbing, J. y E. Theiss-Morse (2002): Stealth Democracy, Cambridge, Cambridge University Press. https://doi.org/10.1017/ CBO9780511613722

Ibarra, P. y I. Ahedo (2008): Democracia participativa y desarrollo humano, Madrid, Dykinson.

Innerarity, D. (2015): La política en tiempos de la indignación, Barcelona, Galaxia Gutenberg.

Isunza E. (2015): Participación ciudadana. Un marco de referencia para la reformulación de las relaciones sociedad-Estado en México, México, Programa de las Naciones Unidas para el Desarrollo.

Jiménez, M. (2011): La normalización de la protesta. El caso de las manifestaciones en España (1980-2008), Madrid, CIS (Colección “Opiniones y Actitudes”, Núm. 70).

Kaase, M. (1999): "Interpersonal trust, political trust and non institutionalised political participation in Western Europe", West European Politics, 22(3), pp. 1-21. https://doi.org/10.1080/01402389908425313

Koselleck, R. (2007): Crítica y Crisis. Un estudio sobre la patogénesis del mundo burgués, Madrid, Editorial Trotta.

Lee, C. W. (2011): "Five Assumptions Academics Make About Public Deliberation, And Why They Deserve Rethinking", Journal of Public Deliberation, 7(1), Article 7. Disponible en: https:/www.publicdeliberation.net/jpd/vol7/iss1/art7 [Consulta: 15 de agosto de 2019]

Martí-Costa, M. (Coord.) (2009): Teoría y significado de la participación no institucionalizada en Aragón, Bellaterra, Institut de Govern i Polítiques Públiques.

Martínez-Palacios, J. (2021): "La burocratización neoliberal de la participación ciudadana en España", Revista Internacional de Sociología, 79(2), e184.

http://doi.org/10.3989/ris.2021.79.2.20.48

Mccaffrie, B. y S. Akram (2014): “Crisis of Democracy?”, Democratic Theory, 1(2), pp. 47-55. https://doi.org/10.3167/ dt.2014.010205

Merkel, W. (2014): “Is There a Crisis of Democracy?”, Democratic Theory, 1(2), pp. 11-25. https://doi.org/10.3167/dt.2014.010202

Neblo, M.A., K. M. Esterling, R. P. Kennedy y M. J. Lazer, David (2010): “Who Wants To Deliberate-And Why?”, American Political Science Review, 104(3), pp. 566-583. https://doi.org/10.1017/S0003055410000298

Nino, C. (1997). La constitución de la Democracia Deliberativa, Barcelona, Gedisa.

Offe, C. (2006): "Political disaffection as an outcome of institutional practices? Some post-Tocquevillean speculations", en M. Torcal y J. R. Montero, eds., Political Dissatisfaction in Contemporary Democracies, London, Routledge, pp. 23-45.

Parés, M. (2009). Participación y calidad democrática. Evaluando las nuevas formas de democracia participativa, Barcelona, Ariel.

Pharr, S. J., R. D. Putnam y R. J. Dalton (2000): “A Quarter-Century of Declining Confidence”, Journal of Democracy, 11(2), pp. 5-25. https://doi.org/10.1353/jod.2000.0043

Piedra Buena, C. A. (2007): "Crisis de partidos políticos en la Argentina: aproximación a un diagnóstico de su situación actual”, en G. Ancarola et al., Calidad institucional o decadencia republicana, Buenos Aires, Lajouane, pp. 179-204.

Pindado, F. (2009): "La participación ciudadana, la vida de las ciudades”, en I. Celaya, dir., Participación ciudadana para una administración deliberativa, Zaragoza, Gobierno de Aragón, pp. 119-148.

Portos, M., Bosi, L. y L. Zamponi (2019): "Life beyond the ballot box: the political participation and non-participation of electoral abstainers", European Societies, 22(2), pp. 231-265. doi: 10.1080 / 14616696.2019.1610785

Przeworski, A. (2019): Crises of Democracy, New York, Cambridge University Press.

Rodríguez, R. (2013): "El triunfo y las crisis de la democracia liberal”, Política y Sociedad, 50 (2), pp. 657-679. https://doi. org/10.5209/rev_POSO.2013.v50.n2.38989 
Roll, D. (2018): “La crisis de la democracia y sus antídotos”, Analecta Política, 8(14), pp. 7-16. https://doi.org/10.18566/apolit. v8n14.a01

Rosanvallon, P. (2006): La contre-démocratie. La politique à l'âge de la défiance, Paris, Seuil.

Sanz, R. (2002): El cinismo politico de la ciudadanía española: una propuesta analítica para su estudio, Madrid, CIS.

Subirats, J. (2005): “Democracia, participación y transformación social”, Polis: Revista de la Universidad Boliviana, 12, pp. $1-10$.

Stefan Foa, R. y Y. Mounk (2016): “The Danger of Deconsolidation”, Journal of Democracy, 27(3), pp. 5-17. https://doi. org/10.1353/jod.2016.0049

Tejerina, B., I. Martínez, B. Cavia, A. Gómez y A. Iraola (2005): Encuesta sobre El movimiento por una justicia global en España, Bilbao, Universidad del País Vasco.

Torcal, M. (2014): "The decline of political trust in Spain and Portugal: Economic performance or political responsiveness?", American Behavioral Scientist, 58, pp. 1542-1567. https://doi.org/10.1177/0002764214534662.

Torcal, M. y J. R. Montero (2006): Political disaffection in contemporary democracies: social capital, institutions and politics, London, Routledge. https://doi.org/10.4324/9780203086186

Tormey, S. (2014): The End of Representative Politics, Londres, Wiley.

Valencia, A., F. Vallespín, J. Subirats, A. Cortina (2013): Crisis y democracia, Sevilla, Fundación Pública Andaluza, Centro de Estudios Andaluces.

Velasco, J. C. (2009): “Democracia y deliberación pública”, Confluencia XXI. Revista de Pensamiento Político, 6, pp. 70-79.

Walker, E. T., M. Mcquarrie y C. W. Lee (2015): "Rising Participation and Declining Democracy", en C.W. Lee, M. McQuarrie y E.T. Walker, eds., From Democratizing inequalities: Dilemmas of the new public participation, New York, New York University Press, pp. 3-23. https://doi.org/10.18574/nyu/9781479847273.003.0001 
